\title{
The Dancing Picture - The Ritual Dance of Native Australians
}

\author{
"How beautiful are the feet of them that bring \\ glad tidings of good things!" (Romans 10:15)
}

Native Australian ritual was to a great extent performed as dance. In many anthropological reports, the term 'dance' is used as a synonym of "perform a rite'. To say that "the men danced Goanna" means that the men performed a rite pertaining to the mythical Goanna lizard. Even now, dance is used both as a religious rite and as a means to revive and present Native Australian culture for Westerners. The dance is accompanied by rhythmical clapping, short songs, sometimes also by playing the Native Australian trumpet, the didjeridoo. Another important item of the ritual dance is the bodily decorations, representing various mythical personages. Thus, dance, music and picture are interwoven in a significant whole referring to the mythical dimension of existence, the Dreaming.

Two items will be discussed in this respect. First, the communicative faculty of the ritual dance will be surveyed. What kind of message does or did - the dance convey to the Native Australians? Several types of communication can be distinguished in ritual dance. There is the narrative aspect, i.e., the dramatization of a myth, or of certain social relations, there is an aspect of explanation, i.e., the visual performance of significant conditions, an expressive aspect of worship, and even an aspect of transmission, as when the body of the dancer is thought to mediate divine power to the audience. When a dancer is considered possessed, the boundaries between his human identity and the divine are wiped out (Hanna 1987: 205210).

This last aspect leads us to the second item of interest regarding the ritual dance in Australia, an issue that has been discussed at length regarding masked dancers in other societies, i.e., the question of whether the dancer is identified with the being represented, or merely performs as an 
actor in a play ${ }^{1}$. In this discussion, the very technique of dancing may have some explanatory faculty, at least as long as we are dealing with Native Australian ritual dance.

\section{The Setting}

The religious notion of the supernatural source of every living being was rather concretely expressed through the belief in "spirit children", i.e., the substance left by mythical actors on the earth, in water pools or in certain natural formations to get incarnated in plants, animals and human beings. The faculty of creating life was entirely a property of those mythical personages, the Dreaming heroes, who also shaped the earth, instigated social rules and created rituals for keeping the world alive and nature abundant. When they disappeared they left their creative essence behind to be called forward by men in ritual. Every human being is alive due to a part of this Dreaming substance having vitalized the foetus. Consequently - but apparently this was seldom clearly put - Dreaming powers were necessary to vitalize nature, make plants grow and carry fruit, and animals to bear young or birds to lay eggs. But even if these facts were not always expressed in terms of ontology, they underlie practically all ritual activity. Through his spiritual descent, man is related to the Dreaming ancestors to the extent that prayer and sacrifice are unnecessary in the communication with these sacred beings and their power, as T. G. H. Strehlow points out (1978: 14). This is not a trait special for the Central Australian peoples, discussed by Strehlow, but noticeable in many other areas. The religious duties were not so much to keep contact with the supernatural beings as to administer their powers to the well-being of the world.

Since early contact times, it has been noted that dance is an important and much-liked part of Native Australian life. There are "open" dances (the so-called corroborees) that may be seen by anyone, blacks or whites, and where anybody is able to participate, by shuffling around, or clapping the rhythm. These dances have a desirable social function: the delight of coming together and meeting friends and relations from distant parts of the land. But even in these all-profane gatherings there is always a reference to the Dreaming dimension and the dancers are not altogether ordinary human relatives and friends, as they also bring the Dreaming substance in

\footnotetext{
${ }^{1}$ For a survey of the theories of the identity between the mask bearer and the character represented, see Pernet 1988: 123-127.
} 
their persons. Moreover, both open and secret dances relate events in the mythical past, and repeat the actions of the Dreaming heroes, their wanderings and deeds. Thus, the dances in an open ceremony are similar to the secret, ritual dances in content or in technique. The difference lies in the significance of the songs (there may also be special, secret songs to the ritual dance) and the movements of the body, in the selection of participants, and, of course, in general attitude (Berndt and Berndt 1988: 382). The ritual dance brings about more than personal well-being for the people present: it conveys life and well-being to the earth.

One of the most awkward problems of studying Native Australian religion is that so much is held secret of the ritually effective actions. Anybody is entitled to read the Bible, and through this reading get information of certain Jewish and Christian beliefs. But the greatest part of Native Australian religious knowledge is concealed from everyone except those who have got access to it through a personal initiation. This is a central principle in the religious thinking: that religious knowledge is personal, private and impossible - mostly dangerous - to reveal to the world at large. Nowadays, most anthropologists have acknowledged this fact, now and then making small excuses in their publications for not reporting every detail of, e.g., a song, or there are requests for caution in the end paper, such as: "this book should be used only after consultation with local male religious leaders" (Berndt 1974). In some open ceremonies there may be parts closed to others than the specially initiated, and thus everyone else has to crouch down or cover his or her eyes to ascertain that the secret parts are seen exclusively by the select group (Berndt and Berndt 1988: 383).

The theme of an open dance does not necessarily have to be related to mythical events. Recent events or significant circumstances may be commented upon as a dance drama, ridiculous points being stressed. The Berndts describe a satirical dramatization of a policeman, leading some young women, all roped together, to a court to bear witness. Now and then another actor tried to take away one of the girls, but the policeman chased him away, wanting to keep all the young women for himself. The Berndts conclude: "The side play, gestures and impromptu remarks of the actors, punctuating the singing, kept the audience in a state of hilarious laughter for over an hour" (Berndt and Berndt 1988: 385).

However, the mythic events constituted the theme of many of the performances, particularly in secret rituals, but also in open ones. After all, there is a notion permeating the lives of the Native Australians to anchor their existence in the dimension of the Dreaming, which in older days 
meant walking the same tracks as the mythical ancestors had wandered, living close to their life-giving substances, and repeat their actions in ceremonies. Today it constitutes the raison d'être of the land rights' movement, and in this respect open corroborees can be useful. Like so many other indigenous peoples, threatened by extinction through a dominating Western culture, Native Australians have started a revivalistic movement to show white Australians that they have a culture of their own, well worth preserving and fostering. Art exhibitions are one means to this end; public dance performances are another. Several dance companies have been created for this end, presenting their shows on occasions such as "Aboriginal Day" or "Aboriginal Week". It also happens that the groups come together for a big gathering, dancing for each other, and for the public, just as people used to do before at the big initiation assemblies. Some of these groups have been abroad to entertain people in various Western cities and others assist tourist agencies to illustrate "Aboriginal Life" for charmed overseas visitors. But this policy is in itself a concession to Euro-Australian demands. It implies an objectification of an ideology which did not distinguish between "culture" and "politics", as Western ideology does. In Native Australian tradition, land rights ("politics") and dance performances ("culture") were two parts of the same concept, i.e., man's affinity with nature, and with the land through his Dreaming connections. The inability of EuroAustralian authorities to grasp this subtle complex of notions has forced the Native Australians to present them as objects of "culture", e.g., products and performances, or of "politics" such as questions of ownership and authority (see for example Merlan 1989).

\section{The Dance}

The ritual dances consisted of short, intensive rythmic and imitative sequences, accompanied by song-lines, clapping with the hands (this could be the only contribution from the women in open corroborees) or with sounding sticks, or in certain areas, the didjeridoo. They were performed on a spot that had been prepared in the bush at a certain distance from the general camp for this particular reason. It was often held that the size and form of the dance place had been designed by the mythical ancestors. In some dances, the representations of the actors were obvious. Some imitated a kangaroo's hopping, or the jerking wovements of a small bird, the crawling of a goanna or the howling of a wild $\mathrm{dog}$. In other cases, the movements 
consisted of a mere stamping or shuffling, and the characters were shown by the song-lines and the body decorations.

The song-lines referred to the myth of the danced personages. Native Australian mythology concentrates on the wanderings of the Dreaming ancestors, carefully indicating the exact localization of their tracks in the ordinary geography. What the ancestors did on a certain spot was almost less interesting than where this spot was situated. In the Aboriginal worldview, localization was, and still is, the basic notion. "All cosmology focused on discrete, known, observed sites" (Swain 1993: 29). This is expressed in the careful establishing in geographical terms of where things happened in the myths. When the actions of the mythical heroes on these sites, e.g., meetings, eating or hunting together, quarrelling, even killing, were reproduced in the dance, it happened in a stylized way, just as the songs and the dance-place were stylizations of the mythical story. The code was wellknown to each participants - but it would not have been so for the noninitiated.

In the accompanying songs the myth was told in highly condensed form. A myth on the saw-fish, rendered on Groote Eylandt to the north-east of Arnhem Land was condensed to seven words only when it was chanted in a dance. Mountford relates:

\footnotetext{
"The sting-ray, Imadoija, and the saw-fish, Ingurudungwa, both members of the oranikapara moiety, travelled together during creation times.

These ancestors began their journey at Wunda-wunda, a place near a small fresh-water creek in Bennett Bay [...]. Leaving Wunda-wunda, the pair entered the water and, travelling round Cape Barrow, camped at Amataita, where the saw-fish ancestor made a small fresh-water creek. From Amataita the stingray and the saw-fish set out eastward for Groote Eylandt, transforming themselves from human beings to sea-creatures. On reaching the western shore of Groote Eylandt they continued their journey overland, the saw-fish cutting out the channel of the present Angoroko River. Finally, the saw-fish and stingray reached Urulgurupa on the eastern coast of Groote Eylandt, near Lake Hubert. This was their final camp. Today their bodies are groups of rocks on the sea-shore" (Mountford 1956: 33).
}

The myth was condensed in these words when it was chanted in a ceremony held in 1948 and recorded by Mountford: "saw-fish/saw on nose/rested/walked/ran/country belonging to saw-fish/sleeps", i.e., the sawfish travelled to a certain locality, resting and sleeping many times on his journey (Mountford 1956: 33-35).

Just as the ceremonial songs consisted of certain key words from the myth, rendering it in a condensed form, the dance place represented the area over which the protagonist travelled, but compressed. The dance place 
does not even have to be in the same area as where the mythical ancestor walked, or close to it. As soon as a ritual has been set in motion through songs and paintings on a certain cleared area, the place is transformed into the area mentioned in the myth. The localization of the place into the mythical geography can also be done by shouting the names of the sites and areas relevant to this part of the myth. This means that a ritual to strengthen a piece of land can take place far away from that special area.

It is assumed that every dance was invented by the mythical ancestors and transmitted to a chosen human individual. This can happen in a nocturnal dream, where the ancestor teaches the dreamer every detail of the dance, the steps, the decorations and the song lines. Then he, or she, has to teach other people this new dance, which may happen at the big assemblies, earlier very often at initiation gatherings. In this way, dances can be spread to far distant areas; in fact, dances have constituted an important item of trade (McCarthy 1939: 83-86). Even in the last decades, the mythical ancestors have continued to make up new dances, and to instruct certain religiously gifted people, also where the dances are not related to a certain land area (see for example Engelhart 1991). Nowadays a dance is first spread amongst domiciled Aborigines in stations or in the small towns, and later brought to larger assemblies. Some of these rituals are connected with new, far-spread cults, primarily in the northern and northwestern areas (see, for example, Kolig 1979; Meggitt 1966; Petri 1950; Petri 1967). Dances may be known to a wider public at the meetings of such cults, or at dance gatherings where various dance groups from all over Australia come together for shows, like the big Aboriginal Dance Gathering on Groote Eylandt in the late 80's. But also at a profane gathering like that one, open to whites as well as all kinds of Aborigines, there is always an allusion to sacred dimensions of the world, through references to the mythical ancestors and their deeds.

The step sequences in a dance are very short, lasting for less than a minute, maybe just 10 to 15 seconds. Royce (1977) has discussed "size units", comparing meaningful units in European ballet - which are the steps, "all named and fitting into phrase lengths" (Royce 1977: 33) - with similar units in some Mexican dances, where the size units are much longer. It may seem as if the short sequences in the Native Australian dance constitute the meaningful units. The myth or the event dramatized is split up into small parts, each characterized by one or two special song-words, and a small number of steps, often ending with a confirming shout. The sequences may be more or less clearly imitiating the movements of the ancestor represented. Some dancers have displayed a remarkable skill in acting 
like a certain animal, to the extension almost of acrobatics. But when, say, the dancer imitates the wriggling of a snake on the ground for a few seconds, while words from a snake myth are sung, and then gets up, this short sequence refers to a walk made by an ancestral snake from a defined place in nature to another well defined place that may be localized far off. It is hardly possible to recognize smaller units carrying a narrative meaning. But the wriggling position itself carries a significant meaning, namely that this dance refers to or even repeats the travelling of a certain ancestral snake, maybe even the Great Snake himself, who is associated with waterholes, rain or flooding and was known all over Australia (Mountford 1978: 25).

Furthermore, each single step may confer meaning through its very style. An organized dance is always a system of symbols, referring to parts of a tale (the narrative aspect) or to social, political or mythological circumstances (the expressive aspect) but it is also always a flow of concrete bodily movements. This rather simple fact tends to be overlooked to the benefit of the symbolic content of these movements. "Since movement is the essential material of dance, it is amazing how little this basic element has been explored in most of the published work on dance," the danceanthropologist Lange states (Lange 1975: 41). One explanation for this negligence is certainly the difficulty of talking of movements at all. Not until Rudolph von Laban constructed a practicable notation system containing symbols for time value, direction of movement, part of body doing the movement and level of execution (Royce 1977: 45) did it become possible to describe dances of any kind in an "etic" way. However, just as musical notation demands a special skill of reading, dance notation has to be thoroughly learnt before the symbols start to make sense, and I am not going to even try to describe the bulk of the movements in Native Australian dance by using some dance notation system $^{2}$. I will just point out a small detail of the movement complex as being clarifying in an analysis of Aboriginal ritual dance, namely, the steps, which may impart knowledge as to important features of a group's world-view. This is rather clear in a comment to the dance gathering on Groote Eylandt made by the Czech choreographer Jiri Kylian ${ }^{3}$. For Kylian, dance is primarily motion, bodily actions, and to renew his own choreography, he studied the bodily language of Aboriginal dancers. One conspicuous feature is the close contact with the

\footnotetext{
${ }^{2}$ Most of the various systems are developments of Laban's notation.

${ }^{3}$ I am grateful to Michael Frankenstein for having drawn my attention to the film on Jiri Kylian's research, released by Arts International.
} 
ground. Many steps are executed in a stamping style, stirring up the dust of the dance place to whirling clouds. There are various kinds of stamping steps, depending on the theme of the dance, i.e., which ancestral being is represented. Animals and birds are to a very great extent characterized by their movement patterns, their way of walking and turning. In Native Australian learning, there was of course a thorough knowledge of these movements, as can be expected of former hunting and gathering peoples. Hundreds of different ways of walking or stamping had been developped in the various dances.

Shuffling is another frequent feature in the dances. Shuffling means an unbroken contact with the ground, it raises extensive dust-clouds, and it leaves distinct marks on the earth. In a shuffling dance, the imitative facet has been toned down. The steps seem to express other aspects of the Dreaming dimension than the copying of mythic deeds. However, shuffling steps can be united with movements of the arms and body that may have a reference to some special mythical ancestor. Besides, shuffling is also a way of walking and may thus represent somebody's travel over a certain area.

In contrast to the earth-bound shuffling, there are also high jumps. These jumps intrigued Kylian, since they were made without the preparation necessary in European classical ballet, where much stress is laid on airiness, lightness and an upwards direction. Native Australian dancers do not have to "go down into the earth" to prepare a jump, since they are firmly connected to it all the time. Their dance was "something very earthy", Kylian noticed.

Thus, also the very style of the steps executed throws light upon some basic notions manifested in the Native Australian dance. Stamping, shuffling and jumping directly from the ground without foregoing preparation express the tight bonds with the land itself, the land which is a central theme of Native Australian religion, in fact, it constitutes the central theme. Everything in the Aboriginal world-view revolves around the connections with land, sites and tracks. The land is not held sacred as a symbol for something else, a transcendent being, or a community, but sacred in itself, as land, as geographical area, as nature, a this-worldly element. The firm connection with the ground is a connection with the sacred dimension of life. Thus, the dance as an instrument of ritual manages to concentrate a whole complex of belief into the movement of the human body. 


\section{The Dancers}

Both men and women can perform dances, but ritual dances have in the overwhelming majority of cases been performed by men. Even when female characters have been impersonated, their parts have been played by men ${ }^{4}$. The rituals were mainly a male business, even though it has been reported from some communities in the later decades that there are special rituals that belong to and are carried out exclusively by women (see, for example, Bell 1983; Berndt 1949; Berndt 1950; Chesson 1983; Kaberry 1939). Although men are the active performers, the presence of women is often required, as food providers, commentators, or rhythm musicians, clapping hands or thighs to the songs. Sometimes they have to "witness" a dance in a passive way, crouching under blankets, hearing everything but not seeing anything. Women in a special social relationship to the actors can participate in parts of the dancing, e.g., at initiation rituals (see, for example, Meggitt 1962: 291; Warner 1958: 257; 276).

The dancers decorate their bodies for the performance. Since the Native Australians in earlier times did not wear any clothes, they had no special dresses for dancing. Instead the decorations were painted directly upon the body. Nowadays the upper part of the body is stripped of clothes and painted. Lines, dots or depicting drawings are painted with red or yellow ochre, white clay and charcoal. In Arnhem Land the patterns can be made with thin brushes but in other areas the fingers are used to draw the lines. The decorations can also consist of feathers, birds' down and shells. For a secret ritual, blood is let from an arm vein or from the penis and when it has coagulated a little, it is spread on the body as glue for the decorating birds' down.

The decorating process constitutes part of the rite. The right to wear a certain pattern depends on a man's spiritual descent. He is said to be the "owner" of this special pattern that is said to have been invented by his mythical ancestor, who has deposited the "child substance" that animated him. It is also assumed that the dance that he afterwards performs has been invented by the same mythical ancestor. In the western and northwestern parts of Australia the man who helps with the painting should belong to the opposite moiety from the dancer himself. This co-operation between moieties is reciprocal. During the painting, certain song-lines have

\footnotetext{
${ }^{4}$ Because of that, I will use male forms of pronouns exclusively when speaking of the dancers. However, the reader will keep in mind that when it comes to the ontological aspects of "double descent", the male form is used as grammatical gender only.
} 
to be sung to call forward the mythical hero that should be impersonated in the dance. To make the ritual effective, the power of the mythical dimension has to be actualized. If blood is used, it may have this mythical power, and in some cases, song-lines also have to be sung when the blood is let.

Other decorations used in the dances are bunches of leaves, tied round wrists and ankles, or held in the hands. In Central Australia, poles could be carried in the dance, painted and decorated with feathers or leaves (Meggitt 1962: 292). Also elaborate head-dresses were used, sometimes even covering the dancer's face and upper part of the body (Isaacs 1984: 62). Some dances demand that the actor carries a string cross on his shoulders. The cross could be made by two oblong boards, lashed together at rightangles. The arms of the cross are united by strings of hair into a diamond-like shape. The string-cross can also be decorated with paint, blood and feathers (Meggitt 1962: 299). Every detail of the body pattern and other dancing paraphernalia refers to some Dreaming character or symbolizes an event in the relevant myth.

\section{The Message}

The message of the dance in an open corroboree is often of an historical, commemorative or entertaining kind. The audience and the dancers become bound together by the common memories acted out in the dance, in addition to the general well-being fostered by a social get-together. But dances are also a kind of "infotainment" utilized in the training of children. Teaching the children to dance is an important facet of up-bringing and it can be done at any time at pauses during the day, or at the evening in the camp. In the dance, the stories of the Dreaming events are visualized and the children become familiar with the traditions of their society. Particularly important are the myths pertaining to a child's "own" Dreaming ancestor and the land where he or she travelled, which is the land that the child itself belongs to. Every child, females and males alike, should have knowledge of its own Dreaming, i.e., the mythical ancestor, and learn at least the open dances associated with it. Earlier, the myth, the dance, and the land areas could in many cases be concretely connected, since the myths could be told in the landscape where the primordial events had taken place. Nowadays it is desirable for knowledgeable grown-ups to have a chance to visit schools to teach the black children mythology and dances ${ }^{5}$.

\footnotetext{
${ }^{5}$ However, not all schools are co-operative in this respect!
} 
In the open corroborees they get an opportunity to imitate the grown-ups and to train their dexterity together with the more skilled. Their mythological-historical knowledge will be reinforced through the visualization of the events so that the dancing performances strengthen the transmission of knowledge in a nice and merry way.

Though most Native Australians have been forced to "emigrate" from their old living areas into stations or towns, many of them still build their identity upon the concept of the mythical ancestors, who were born out of the land itself. Thus, the central notion of the belief in the life-creating Dreaming powers is locality. Individual, space and myth are indissolubly interwoven in a coherent whole to the extent that myth is almost identical with land, and the human beings are thought of as being born out of the land, belonging to it and being responsible for its well-being. "To take care of the land" is a still acknowledged duty which in early-contact times was currently done, either in the course of the day, or at specially staged ritual occasions. Nowadays, this obligation meets great obstacles, since the Native Australians have been forced away from those land areas that they had to "grow up" and tend. In traditionally oriented groups, however, people try to get out in the bush by truck to perform the reinforcing rites and get strengthened themselves by the closeness of the land.

When the dance place has been constructed according to the directions of the Dreaming ancestor whose dance should be performed, and when the dancers have been decorated according to those directions, the song-lines chanted and the dance performed call forward the situation where the mythical hero him- or herself acts on the surface of the earth. The deeds of the Dreaming characters created the forms of the world and the flow of events, the results of their actions being clearly visible and tangible in the geographical landscape. Hills, stone clusters, riverbeds, waterholes, trees and everything existing are remnants of the mythical characters' wanderings. But these deeds can be repeated by their spiritual descendants, the Aborigines, and it is highly desirable that they are repeated, because otherwise the land would suffer privations. The participants of the rite are the representatives of the Dreaming actors by virtue of their spiritual descent, by social relations or by initiation and as such they are assumed to be capable of duplicating the mythical acts. This creates new life for the land and makes all living things thrive and multiply.

This - to look after and preserve the land - is the main purpose of the secret ritual dances, but in the open corroborees something of this benefical effect is also felt. After all, there are still the same actors performing, i.e., the characters of the Dreaming dimension, through their human represen- 
tatives. The commemoration of the ancestral deeds is a source of personal well-being for every person present and even if the performances are open, not secret, they keep the quality of sacredness that permeates the secret rites. In Native Australia, sacred is not identical with secret. It is a quality that clings to everything associated with the Dreaming dimension, and this dimension meets the knowledgeable Aborigine everywhere in the land and in society. Watching a dancer impersonating the primordial Goanna ancestor, or the primordial Rock Wallaby ancestor, the audience is reminded of the blessed works of these ancestors.

\section{Who Is the Dancer?}

This takes us to the second item mentioned in the introduction, the question of the identity of the dancers. I do not pretend to be able to solve this problem at all, since it is a rather thorny subject which touches on all kinds of masked dancing where supernatural characters are assumed to be present. The Native Australian ritual dancing is virtually a kind of masked dance, even when the face of the dancer is seen, which is not always the case. Some dancers have to cover their faces entirely with feathers and in some dances the face is painted all over with clay. But the body decorations dress the actor in a stage costume relevant to the particular dance to be performed, which involves a transformation of his personality into one of the Dreaming characters. The question is: how far is this transformation accomplished?

The body painting part of the rite is said to transform the dancer to his mythical ancestor and to make him a part of the Dreaming, if it is done correctly. This identity is built up partly through the painting and partly through the singing. It can be expressed as to "sing" the decoration on the body by the painting assistants. By this procedure the borders between the everyday person of the dancer and his mythical ancestor are wiped out. The actor in the dance is in fact the Dreaming being, not the human individual (Elkin 1961: 205). This has also been stated by the Berndts: the dancer did not only feel that he played the role of his mythical ancestor, but he felt that he actually identified with this character (Berndt and Berndt 1988: 239). Meggitt has also asserted this: "The people believe that, by performing the appropriate rituals and songs, living men can actually 'become' these beings for a short time and so participate briefly in the dreamtime" (Meggitt 1962: 60). At the same time, he feels his relationship with the natural object that is the other incarnation of his ancestor's spiritual 
depositions, and whose movements should be copied in the imitative dance styles.

"Identification" is here not equal to the extinction of consciousness or self-awareness. Pernet (1988: 123-139) has convincingly shown that a dancer impersonating a sacred being far from losing his self-control needs to keep it through the whole dance: “... loin de se laisser aller à son délire et à sa frenesie, le danseur doit jouir de toute sa concentration et être pleinement conscient de ce qu'il fait afin de respecter le pas et les rythmes..." (1988: 132). Hanna's statement that "iconic" dancers, i.e., dancers that are regarded as impersonating some deity, are "found among groups who believe in possession" (Hanna 1979: 41) must be taken cum grano salis magno in this respect. Possession is not a characteristic feature of Native Australian religion.

Equality, however, is. The dominant factor of this circumstance is the belief in the double mode of existence. Man is human, different from plants and animals, subject to Nature's laws of growing, ageing and death, but he is also to the same extent a divine being through his spiritual descent. Because of this, every human is a part of the abiding existence of the Dreaming, which is time-less and unchanging. It is this Dreaming-part of the dancer that is actualized in the performance, by localizing the dance place to a spot that had been trodden by the relevant ancestor, by putting on the decorations made by her or him and by singing the song-lines pertaining to the myth. The dancer keeps his human character while acting out the Dreaming part of his personality.

However, spiritual descent is not the only way to partake of the Dreaming dimension of the world. There is also the possibility for an individual to extend his ritual area of action by getting initiated into cults that belong to other mythical ancestors than the one who deposited the spiritual substance animating him. A man with extensive social contacts can get admission to several such cults. The crucial precept would be that the Dreaming essence actualized in the cult is transferred to him through men who already had a part of it, usually men with the right spiritual descent, "owners" of the cult, or, as in the case of non-localized cults, by initiated men. It was not unusual for this initiation to be part of trade or other alliance negotiations. Still, the identification with the Dreaming ancestor impersonated was recognized by the participants and by the on-lookers, if any. 


\section{The Land in Dance}

Let us now return to how the style of dancing may show a central aspect of the Aboriginal world-view. The dancer expresses, as has been stated above, his share in the Dreaming. When he dances, he "becomes" the impersonated character. But those characters, impersonated in the ritual dance, the Dreaming ancestors, have a very special connection with the land itself, with the ground and everything that has come out of this ground. In fact, they themselves are impersonators, i.e., they act as personifications of the land, or parts of it. In most of the myths, it is said that the Dreaming heroes emerged out of the land and sank back into it when they had finished their work on it. The sites where they had emerged or wandered or disappeared are regarded as sacred, not secondarily because of the divine presence there, or as memorials of a divine appearance, but sacred in themselves because of the particularly high concentration of life essence deposited there.

In a recent, and extremely thought-provoking work, Swain (1993) has suggested that in the Aboriginal world-view, time is a nullity; creation is nothing that can be associated with any time, primordial or not. Instead, space is the category solely structuring this world-view, the priority of place appearing in every work of art or imagination. The land emerges, and takes shape as walking mythical heroes, who again shape the land, and eventually go back into it. In the ritual staging, this is expressed partly as localizing the place into some part of the relevant myth, partly as making distinct marks on the ground where the rite is held - marks that after finishing the dance will be swept away.

In consideration of this tight constraint to the earth, it is not surprising that the dancing styles have also been shaped in accordance with the preference of place. Stamping and shuffling are a way to express the bonds between the earth and all living creatures, the human beings and the natural objects that they imitate in dance, which both are descendants from the land-born ancestors. The decorated body, the picture, is a reproduction of the Dreaming hero, the dance is the ancestor dancing and the distinct marks in the sand are the tracks of his feet as the world was created through his walking. These tracks, which shaped the world, are repeated by the dancer's feet and thus the world will be regenerated again and again by the marks of his steps. 


\section{References Cited}

\section{Arts International}

n.d. The Road to Stamping Ground: Aboriginal Dance Gathering on Groote Eylandt. Presented by the Aboriginal Cultural Foundation.

\section{Bell, Diane}

1983 Daughters of the Dreaming. Melbourne: McPhee Gribble.

\section{Berndt, Catherine $\mathrm{H}$.}

1949 Expressions of grief among Aboriginal women. Oceania 20: 286-332.

1950 Women's Changing Ceremonies in Northern Australia. Paris: Herrman. (L'Homme. Cahiers d'ethnologie, de géographie et de linguistique, 1)

Berndt, Ronald M.

1974 Australian Aboriginal Religion. Leiden: E.J. Brill. (Iconography of Religions, 5)

Berndt, C. H., and R. M. Berndt

1988 The world of the first Australians. London.

Chesson, Marlene

1983 The social and economic importance of the women in Jigalong. In: Fay Gale (ed.), We are Bosses Ourselves. The Status and Role of Aboriginal Women Today; pp. 40-43. Canberra: Australian Institute of Aboriginal Studies. (AIAS, n. s., 41)

Elkin, A. P.

1961 Yabuduruwa. Oceania 31:166-209.

Engelhart, Monica

1991 Renewal as Tradition: New cults in Aboriginal Australia. In: Armin W. Geertz and Jeppe Sinding Jensen (eds.), Religion, Tradition and Renewal; pp. 139-148. Aarhus: Aarhus University Press.

Hanna, Judith Lynne

1979 To Dance is Human: A Theory of Nonverbal Communication. Austin: University of Texas Press.

1987 Dance. Dance and Religion. In: Mircea Eliade (ed.), The Encyclopedia of Religion 4; pp. 203-212.

Isaacs, Jennifer

1984 Arts of the Dreaming. Australia's living heritage. Sydney: Lansdowne.

Kaberry, Phyllis M.

1939 Aboriginal Woman, Sacred and Profane. London: G. Rutledge.

Kolig, Erich

1979 Djuluru: Ein synkretistischer Kult Nord-West-Australiens. BaesslerArchiv, N. F., 27: 419-448.

Lange, Roderyk

1975 The Nature of Dance: An Anthropological Perspective. London: Macdonald and Evans.

McCarthy, Frederic D.

1939 "Trade" in Aboriginal Australia. Oceania 10: 80-104.

Meggitt, M. J.

1962 Desert people. A Study of the Walbiri Aborigines of Central Australia. Sydney: Angus \& Robertson. 
1966 Gadjari among the Walbiri Aborigines of Central Australia. Sydney. (Oceania Monograph, 14).

Merlan, Francesca

1989 The objectification of "culture": an aspect of current political process in Aboriginal affairs. Anthropological Forum 6/1:105-116.

Mountford, Charles $P$.

1956 Art, myth and symbolism, Records of the American-Australian scientific expedition to Arnhem Land; vol. 1. Melbourne: Melbourne University Press.

1978 The Rainbow-Serpent Myths of Australia. In: Ira R. Buchler and Kenneth Maddock (eds.), The Rainbow Serpent. A Chromatic Piece; pp. 23-97. The Hague: Mouton.

Pernet, Henry

1988 Mirages du masque. Genève: Labor et Fides. (Religions en perspective, 3)

Petri, Helmut

1950 Kurangara: Neue magische Kulte im Nordwesten Australien. Zeitschrift für Ethnologie 75: 43-51.

1967 Wandji-Kurangara. Ein mythischer Traditionskomplex aus der westlichen Wüste Australiens. Baessler-Archiv, N. F., 15: 1-34.

Royce, Anya Peterson

1977 The anthropology of Dance. Bloomington: Indiana University Press..

Strehlow, T. G. H.

1978 Central Australian Religion. Bedford Park: Australian Association for the Study of Religions.

Swain, Tony

1993 A Place for Strangers. Towards a History of Australian Aboriginal Being. Cambridge: Cambridge University Press.

Warner, w. Lloyd

1958 A Black Civilization. A Social Study of an Australian Tribe. New York: Harper. 